\title{
Use of Telemetry Methods to Estimate Natural and Fishing Mortality of Striped Bass in Lake Gaston, North Carolina
}

\author{
Joseph E. HightoweR* \\ U.S. Geological Survey, Biological Resources Division, \\ North Carolina Cooperative Fish and Wildlife Research Unit, Department of Zoology, \\ Campus Box 7617, North Carolina State University, \\ Raleigh, North Carolina 27695-7617, USA \\ JAMES R. JACKSON ${ }^{1}$ \\ Department of Zoology, Campus Box 7617, North Carolina State University, \\ Raleigh, North Carolina 27695-7617, USA \\ Kenneth H. Pollock \\ Department of Statistics, Campus Box 8203, North Carolina State University, \\ Raleigh, North Carolina 27695-8203, USA
}

\begin{abstract}
Natural mortality can substantially affect fish population dynamics, but the rate is difficult to estimate because natural deaths are rarely observed and it is difficult to separate the effects of natural and fishing mortality on abundance. We developed a new telemetry approach for estimating natural and fishing mortality rates and applied it to the population of striped bass Morone saxatilis in Lake Gaston, North Carolina and Virginia. Our analyses were based on a sample size of 51 telemetered striped bass that were known to be alive and in Lake Gaston at least 1 month after capture and surgery. Relocations of live fish and fish that died of natural causes were used to estimate natural and fishing mortality rates and the probability of relocating telemetered fish. Fishing mortality rates varied seasonally, but few natural deaths were observed, so the best model incorporated a constant annual instantaneous natural mortality rate $(M ; \pm \mathrm{SE})$ of $0.14 \pm 0.02$. With the uncertainty in model selection accounted for, the average annual $M$ was $0.16 \pm 0.04$ for 1997 and $0.12 \pm 0.04$ for 1998 . Estimated annual fishing mortality rates $(F)$ were $0.74 \pm 0.13$ for 1997 and $0.34 \pm 0.18$ for 1998 . This telemetry approach for estimating mortality rates does not rely on angler reporting of tagged fish. The relative standard errors for $M(24-33 \%)$ were comparable to those obtained from traditional tagging methods with large sample sizes. This approach is most applicable in closed systems, where fishing mortality estimates are not biased by emigration. A high relocation probability is critical to reliably establishing seasonal changes in mortality.
\end{abstract}

Information about the magnitude of natural mortality is essential for effective management of exploited fish populations. Unfortunately, natural mortality is difficult to estimate directly because natural deaths are rarely observed (Quinn and Deriso 1999). In addition, it is difficult to separate the effects of natural mortality, fishing mortality, and recruitment on abundance, making estimation of any single factor problematic (Hilborn and Walters 1992; Quinn and Deriso 1999). Often, it is straightforward to estimate the total mortality rate but very difficult to partition total mortality into its natural and fishing components. That partitioning is crit-

\footnotetext{
* Corresponding author: jhightower@ncsu.edu

${ }^{1}$ Present address: Cornell Biological Field Station, 900 Shackleton Point Road, Bridgeport, New York 13030, USA.
}

Received September 30, 1999; accepted December 26, 2000 ical to assessing the value of harvest regulation, however.

General approaches for estimating the instantaneous rate of natural mortality $(M)$ include (1) catch curve analysis, (2) regression of the instantaneous total mortality rate $(Z)$ on fishing effort, (3) mark-recapture experiments, and (4) correlation of $M$ with other life history parameters (Vetter 1988; Quinn and Deriso 1999). A catch curve analysis provides an estimate of $Z$ based on the rate at which cohorts decline with age (Ricker 1975); $M$ can then be estimated indirectly by subtracting from $Z$ an estimate of the fishing mortality rate or directly in the special case in which age composition data are available for a period of negligible fishing (Vetter 1988; Quinn and Deriso 1999). One advantage of a catch curve analysis for an unfished population is that it can provide some information about trends in $M$ as a function of age (Ricker 
1975). Estimating $M$ from a regression equation relating $Z$ and fishing effort (Ricker 1975) should be more generally applicable than using a catch curve because the approach can be used with exploited populations. However, the disadvantages of the regression approach include its long-term nature (generally, there is only one data point per year) and the difficulty of estimating fishing effort and of obtaining sufficient contrast in levels of $Z$. Many methods exist for estimating natural and fishing mortality using tag return methods (e.g., Hearn et al. 1987; Hoenig et al. 1998a, 1998b; Xiao and McShane 2000); however, these approaches are difficult to apply in practice because the tag reporting rate must be known or reliably estimated or because auxiliary estimates of fishing effort are required. Methods that relate $M$ to life history parameters such as maximum age or growth rate have been widely used because they require minimal data (Vetter 1988). A major disadvantage of these methods is that the estimates obtained are of unknown and generally low precision (Vetter 1988; Pascual and Iribarne 1993). Also, this approach provides no information about how $M$ might vary seasonally or among ages or years.

Telemetry methods are commonly used to estimate mortality rates for terrestrial animals (Trent and Rongstad 1974; Pollock et al. 1989a, 1989b; White and Garrott 1990; Pollock et al. 1995). The general approach is to relocate live and dead animals at fixed time intervals and determine the number that died between search occasions. A key advantage of this approach is the information that is gained about the timing and causes of mortality. Periods of high natural (nonharvest) mortality can often be linked to harsh environmental conditions (White and Garrott 1990). Because dead individuals can often be recovered in terrestrial telemetry studies, information can also be gained about the sources of mortality, including harvest and various types of natural mortality, such as predation, starvation, and disease (Trent and Rongstad 1974).

Applying these telemetry methods to fish populations would represent a valuable advance because of the potential to better understand the timing and relative magnitudes of different sources of mortality. Unfortunately, it is generally not possible in aquatic systems to observe the animal, so inferences about status (alive or dead) can only be made indirectly. Some transmitters indicate apparent nonharvest mortality by emitting a different signal after a predefined period without movement. Depth- or temperature-sensing transmitters have sometimes been used to establish that a fish was dead because it was located on the bottom or at an unacceptable temperature or dissolved oxygen level (Lee and Bergersen 1996; Bettoli and Osborne 1998). Standard transmitters that output a fixed signal pattern ("pingers") can also be used to infer mortality based on the lack of movement between search occasions (Bendock and Alexandersdottir 1993; Bettoli and Osborne 1998). Relocation data must be interpreted cautiously, however, because multiple relocations at the same site could also mean that the animal had shed its transmitter or simply not moved. Another difficulty with using telemetry in aquatic systems is that the failure of a transmitter would rarely be known. Other practical problems are generally the same as in wildlife studies. Harvest of an animal could be known if the tag is reported (White and Garrott 1990), or it might be inferred based on the disappearance of the transmitter signal. Migration from the study area can also cause disappearance of the transmitter signal and cannot be separated from harvest unless the emigration rate can be estimated.

We developed analytical methods and a protocol for interpreting telemetry data in order to estimate the natural and fishing mortality rates of striped bass Morone saxatilis stocked into Lake Gaston, North Carolina and Virginia (Figure 1). This system provides an excellent opportunity to assess the applicability of telemetry-based mortality estimates to fish populations. The natural and fishing mortality rates of striped bass were unknown but needed for management, and they were thought to vary seasonally. The presence of a downstream reservoir provided an opportunity to detect the nonharvest emigration of fish from the lake. The approach developed here should be generally useful for closed populations in which the magnitude and seasonality of mortality rates are of interest.

\section{Methods}

Field methods.-Fish for tagging were obtained by gillnetting from December 1996 to February 1997 and electrofishing in May 1997. We surgically implanted VEMCO (VEMCO, Ltd., Nova Scotia, Canada) sonic transmitters in captured striped bass of legal size (greater than $508 \mathrm{~mm}$ ) following the methods used by Haeseker et al. (1996). Fish were not given an external tag because we did not want to influence the probability that a fish caught by an angler would either be harvested or released. Each transmitter was labeled with an address and phone number so that 


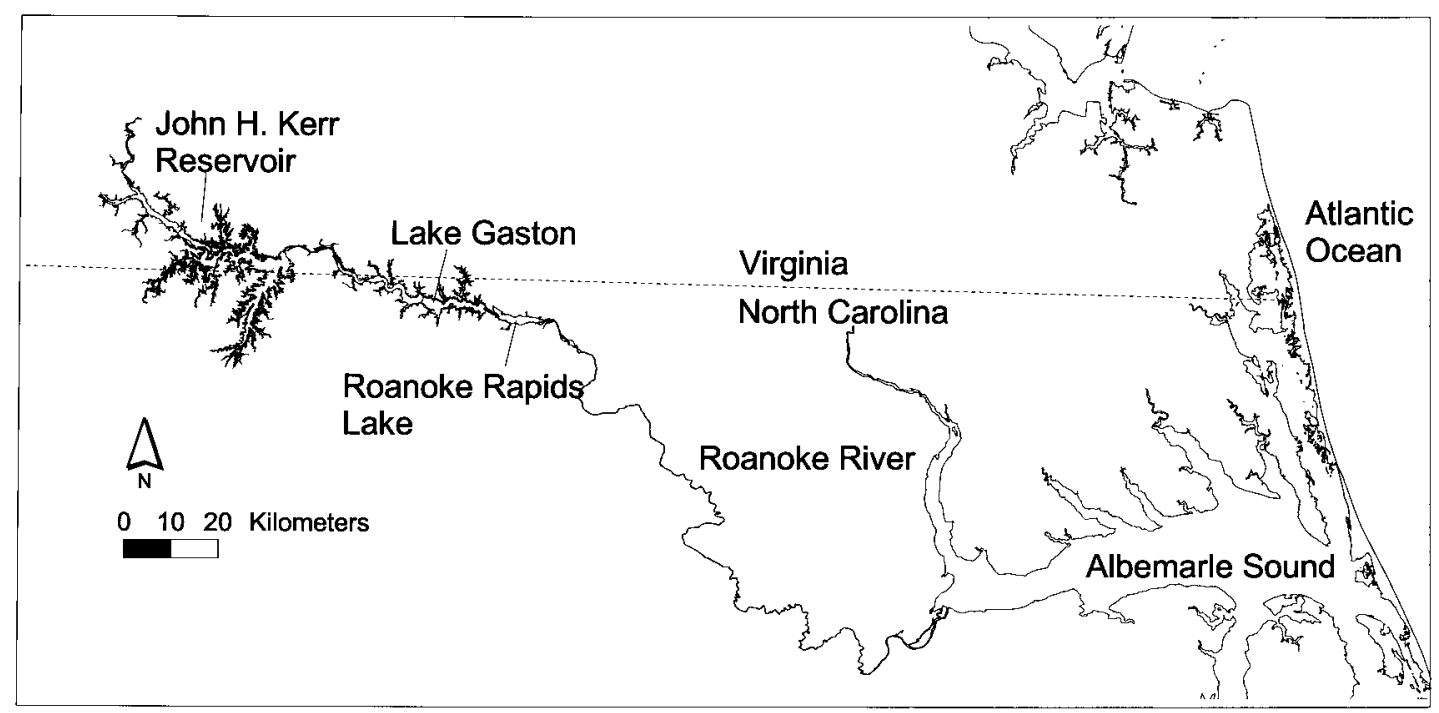

FIGURE 1.-Map of the Lake Gaston study area and adjacent downstream reaches.

an angler could return a detected transmitter for an unspecified reward.

Transmitters were programmed with a 2-weekson, 2-weeks-off duty cycle, which resulted in a 2year battery life; consequently, we searched the lake by boat every 4 weeks between January 1997 and December 1998. It typically required $2 \mathrm{~d}$ to search the entire lake. At sites where fish were relocated, we used a Global Positioning System receiver to record location in Universal Transverse Mercator (UTM) coordinates.

Interpretation of telemetry data.-We assumed that fish that were repeatedly located in the same position had died; their status was generally apparent after two or three searches. Those fish were assumed to have died of natural causes, although we cannot rule out catch-and-release (hooking) mortality. In either case, they were a nonharvest loss to the population of stocked fish. We limited our analysis to fish confirmed to be alive and in Lake Gaston at least 1 month after capture and surgery, so surgery-related mortality and transmitter shedding were assumed to be negligible.

There were four possible explanations for a fish not being located during a search: (1) the fish was present in the study area but the signal was missed; (2) harvest; (3) migration downstream through the dam turbines; and (4) transmitter failure. To relocate fish that had moved through the turbines, we conducted several searches in the reservoir downstream of Lake Gaston (Roanoke Rapids Lake) as well as more limited searches further downstream in the Roanoke River from the Roa- noke Rapids dam to Albemarle Sound (a distance of 221 river $\mathrm{km}$ ) and in parts of Albemarle Sound (Figure 1). We assumed that fish not located during repeated searches of Lake Gaston or downstream of the Gaston dam had been harvested.

Analysis of telemetry data.-Traditional approaches for estimating survival from telemetry data, such as the Kaplan-Meier approach, are based on relocations of live and dead animals but assume a relocation probability of 1.0 (Pollock et al. 1995). Traditional capture-recapture models, such as the Jolly-Seber model, are based on the capture or observation of live individuals but allow for capture (detection) probabilities less than 1.0 (Pollock et al. 1995). Pollock et al. (1995) developed a more general telemetry-based model that linked the Jolly-Seber and Kaplan-Meier methods, allowing for relocation probabilities less than 1.0 and the relocation of both live and dead animals. They used a maximum-likelihood approach to estimate the survival rate (or equivalently, $Z$ ) and relocation probability for each search occasion.

We extended the model developed by Pollock et al. (1995) to allow for separate estimation of natural and fishing mortality rates. By modeling the number of relocated fish rather than the total number at risk, this model accounted for the fact that not all fish remaining in the lake were relocated on every trip. Decreases over time in the number of relocated live fish provide information indirectly about fishing mortality, whereas relocations of dead fish provide direct information 
about natural mortality. Information about relocation rate was obtained when fish were missed and then relocated on a later search occasion.

Following the approach used by Burnham et al. (1987), we considered only the first relocation for each telemetered fish in release $R_{i}$. Fish were tagged with transmitters at times 1,4 , and 6 , and searches were conducted at times 2-27. Thus, a fish tagged at time 1 could be relocated at times $2,3, \ldots 27$, or it might never be relocated. If relocated, the fish could be judged alive (if movement was detectable between searches) or dead (if found at the same site on consecutive searches). If a fish was alive when first relocated at time $i$, it became part of a new (virtual) release at time $i$ +1 . Parameter estimates were obtained by modeling the expected number of fish from the $i$ th release that would first be relocated during searches at times $i+1, i+2, \ldots, 27$. The expected number from release $R_{i}$ first relocated alive at time $i+1$ was obtained as the product of the number released, the survival rate from time $i$ to $i+1$ $\left(S_{i}=\exp \left[-F_{i}-M_{i}\right]\right)$, and the probability of relocating an individual during search $i+1$ $\left(p_{i+1}\right)$ :

$$
R_{i} \cdot \exp \left(-F_{i}-M_{i}\right) \cdot p_{i+1}
$$

where $F_{i}$ and $M_{i}$ represent the instantaneous rates of fishing and natural (nonharvest, including hooking) mortality at time $i$. The expected number from release $R_{i}$ first relocated alive at time $i+2$ would be

$$
\begin{gathered}
R_{i} \cdot \exp \left(-F_{i}-M_{i}\right) \cdot\left(1-p_{i+1}\right) \\
\cdot \exp \left(-F_{i+1}-M_{i+1}\right) \cdot p_{i+2}
\end{gathered}
$$

The term $\left(1-p_{i+1}\right)$ is the probability of not being relocated on search occasion $i+1$. For a Type 2 fishery, in which fishing and natural mortality operate concurrently (Ricker 1975), the expected number of natural deaths from release $R_{i}$ first relocated at time $i+1$ would be

$$
R_{i} \cdot M_{i} \cdot \frac{\left[1-\exp \left(-F_{i}-M_{i}\right)\right]}{\left(F_{i}+M_{i}\right)} \cdot p_{i+1}
$$

The expected number of natural deaths from release $R_{i}$ first relocated at time $i+2$ would be

$$
\begin{gathered}
R_{i} \cdot \exp \left(-F_{i}-M_{i}\right) \cdot\left(1-p_{i+1}\right) \cdot M_{i+1} \\
\cdot \frac{\left[1-\exp \left(-F_{i+1}-M_{i+1}\right)\right]}{\left(F_{i+1}+M_{i+1}\right)} \cdot p_{i+2}
\end{gathered}
$$

It is not possible to determine the timing of natural deaths when a fish is found dead after not being relocated on one or more occasions. Thus, this expression is based on the assumption that the natural death occurs during the interval prior to the search when the dead fish is first relocated. In this study, expressions were constructed for the expected number of live and dead fish first relocated on one to four search occasions after release except for release $R_{6}$, from which fish were first relocated up to six occasions later.

The assumptions of this approach are as follows:

(1) Every marked animal present in the study area (Lake Gaston) at time $i$ (whether alive or dead due to natural causes) had the same probability $p_{i}$ of being relocated on the $i$ th search occasion.

(2) Every marked animal alive and in the study area at time $i$ had the same probability $\left(S_{i}=\right.$ $\left.\exp \left[-F_{i}-M_{i}\right]\right)$ of surviving to the next search occasion because all were of harvestable size when tagged.

(3) The probability of transmitter failure or of a transmitter being shed was negligible.

(4) All animals behaved independently with respect to relocation and survival probabilities.

(5) Fish leaving the study area were harvested or migrated downstream through the turbines.

(6) Fish located repeatedly at the same site died of natural or hooking mortality.

(7) Natural mortality occurred immediately prior to the first relocation at the final site occupied by that fish.

To apply our results to the entire population, we also assumed that marked and unmarked fish had equal survival rates. This assumption should be reasonable, given that telemetered fish had been at large for at least 1 month.

The computer program RELEASE (Burnham et al. 1987) was used to convert the relocation history into a summary table of relocations for each release, which is referred to as a full-m array. This array contained all the information from the original relocation history table, and was used by program SURVIV (White 1983) to estimate the model parameters. Following Burnham and Anderson (1998), we used the Akaike information criterion $\left(\mathrm{AIC}_{\mathrm{c}}\right.$, which includes a correction for small sample size) to evaluate the likelihood of different models, that is,

$$
\mathrm{AIC}_{\mathrm{c}}=-2 \log _{e}[\ell(\underline{\hat{\theta}})]+2 K+\frac{2 K(K+1)}{n-K-1}
$$

where $\ell(\underline{\hat{\theta}})$ is the likelihood of parameter vector $\ell(\underline{\hat{\theta}})$ given the data, $K$ is the number of parameters, 
and $n$ is the effective sample size. The effective sample size is considered to be the total number of telemetered animals released (or rereleased) on all occasions (Burnham and Anderson 1998).

Our global (full) model allowed natural and fishing mortality rates and relocation probabilities to vary by occasion, except that the final three relocation probabilities were assumed to be equal because of the potential confounding between relocation probability and fishing mortality over the final few searches. Reduced models assumed that rates were constant over all occasions or that they varied by year, quarter, or both year and quarter. The model with the lowest $\mathrm{AIC}_{\mathrm{c}}$ value was considered to provide the best trade-off between bias (underfitting) and variance (overfitting) (Burnham and Anderson 1998). Its performance was compared to the other candidate models using scaled $\mathrm{AIC}_{\mathrm{c}}$ values as follows:

$$
\Delta\left(\mathrm{AIC}_{\mathrm{c}}\right)_{i}=\left(\mathrm{AIC}_{\mathrm{c}}\right)_{i}-\min \left(\mathrm{AIC}_{\mathrm{c}}\right)
$$

(Burnham and Anderson 1998). Models with $\Delta \mathrm{AIC}_{\mathrm{c}}$ values within $1-2$ of the best model have substantial support, those with $\Delta \mathrm{AIC}_{\mathrm{c}}$ values of 4 7 have considerably less support, and those with $\Delta \mathrm{AIC}_{\mathrm{c}}$ values greater than 10 are a poor approximation of the data (Burnham and Anderson 1998). For candidate model $i\left(M_{i}\right)$, we determined the likelihood, given the data $(\underline{x})$ as

$$
\ell\left(M_{i} \mid \underline{x}\right)=\exp \left(-\frac{\Delta_{i}}{2}\right)
$$

These estimated likelihoods can be normalized so that they sum to 1 over the $R$ candidate models, that is,

$$
w_{i}=\frac{\exp \left(-\frac{\Delta_{i}}{2}\right)}{\sum_{r=1}^{R} \exp \left(-\frac{\Delta_{r}}{2}\right)}
$$

The $w_{i}$, termed Akaike weights, represent the relative likelihoods of different candidate models.

To account for uncertainty in model selection, we obtained model-averaged estimates of annual mortality rates based on the entire set of candidate models. For parameter $\theta$, the weighted average over all candidate models would be

$$
\hat{\bar{\theta}}=\sum_{r=1}^{R} w_{r} \hat{\theta}_{r}
$$

with estimated variance

$$
\widehat{\operatorname{var}}(\hat{\bar{\theta}})=\left[\sum_{r=1}^{R} w_{r} \sqrt{\widehat{\operatorname{var}}\left(\hat{\theta}_{r} \mid M_{r}\right)+\left(\hat{\theta}_{r}-\hat{\bar{\theta}}\right)^{2}}\right]^{2}
$$

where $\widehat{\operatorname{var}}\left(\hat{\theta}_{r} \mid M_{r}\right)$ is the estimated variance of $\hat{\theta}$ given that model $r$ is correct.

\section{Results}

We restricted our analyses to 51 striped bass confirmed to be alive and in Lake Gaston at least 1 month after capture and surgery (Hightower and Jackson 2000). At least a few telemetered fish were missed during most searches of the lake (Figure 2), probably owing to a variety of factors, including boat noise, fish moving into the area immediately below Kerr Dam (where signals could not be detected during high discharge periods), and the difficulty in separating signals when fish were aggregated. The likelihood of missing fish declined during the second year as our searching ability improved and numbers declined enough to preclude large aggregations.

Based on the pattern of relocations (Figure 2), we consider 30 of the 51 fish to have been harvested during the 2-year period. Only five transmitters were returned by anglers, presumably because of the lack of an external tag. Two fish that were assumed to have been harvested in late 1998 (one last seen on search occasion 25, the other on occasion 26) were only absent for one or two occasions and could simply have been missed during the final search occasions.

Deaths attributed to natural mortality were not common (six fish) and occurred mostly during summers (Figure 2). Uncertainty regarding the timing of natural mortalities affected two fish that were missed on three to five occasions before being found dead. Both occupied final sites with substantial aquatic vegetation, which we found to reduce signal range to essentially zero. Thus, it is reasonable to assume that these fish died 1 or more months earlier but were not relocated until aquatic vegetation died back.

Of the 51 fish known to be alive and in Lake Gaston at least 1 month after tagging, only two were determined to have migrated downstream through the turbines (Figure 2). These were located during a May 1998 search of Roanoke Rapids Lake. One was relocated in Lake Gaston in April 1998, so the timing of passage is known. The other fish was last relocated in Lake Gaston in February, so there is a 3-month window during which downstream passage could have occurred. These two fish were excluded from the analysis after their last relocation within Lake Gaston, so that the es- 


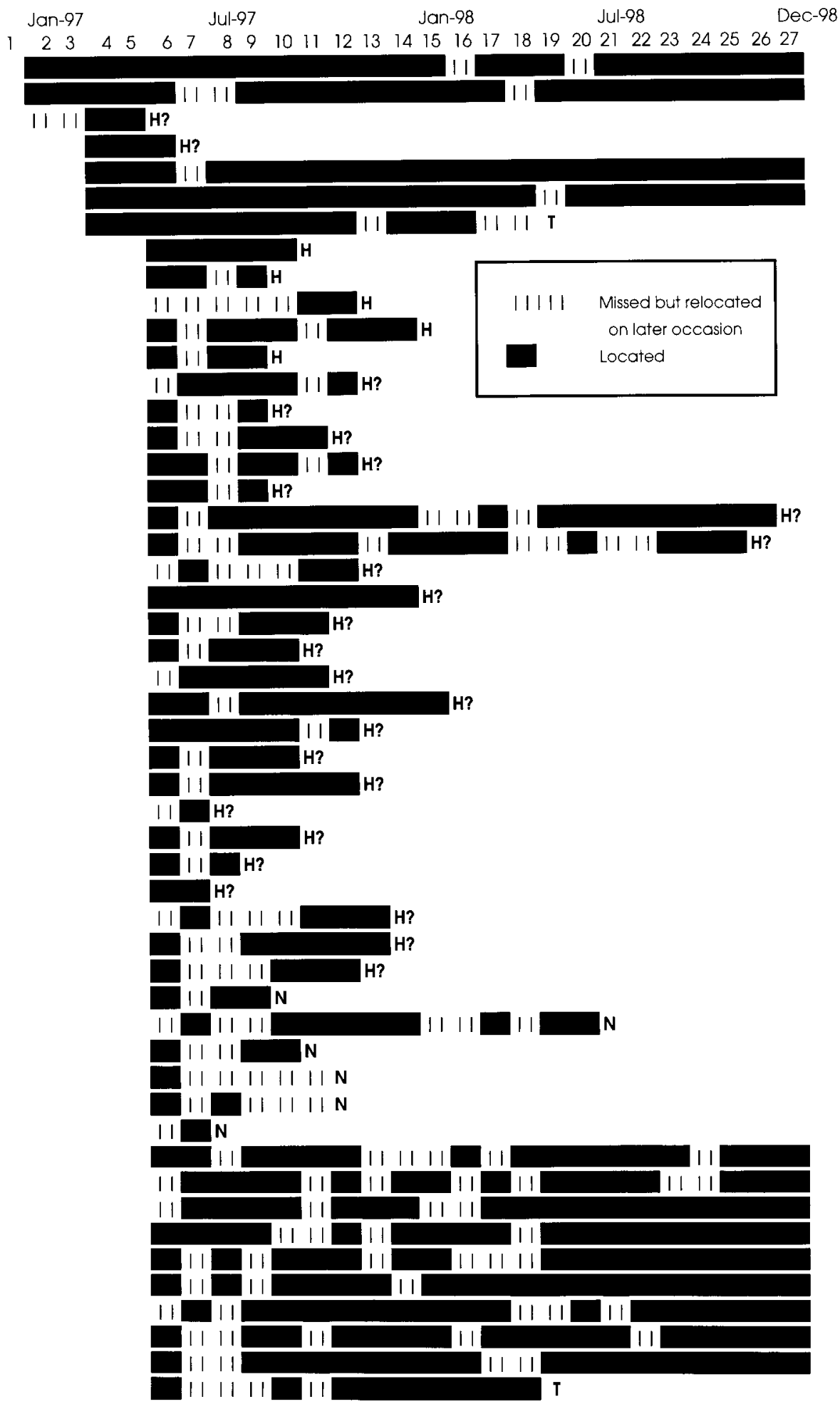

FIGURE 2.-Relocation histories for 51 telemetered striped bass released in December 1996, February-March 1997, or May 1997. For fish not classified as being alive at the end of the study, letters denote their fates as apparent harvest $(\mathrm{H}$ ?), harvest with returned transmitter $(\mathrm{H})$, natural (nonharvest) mortality $(\mathrm{N})$, or turbine passage $(\mathrm{T})$. 
timated $F$ s would not be biased by known emigration.

Fishing mortality rates for the full model showed a strong seasonality that was generally captured by reduced models with $F$ varying by quarter and year (Figure 3). Natural deaths were also highly seasonal but few in number (Figures 2-3). On the basis of $\Delta \mathrm{AIC}_{\mathrm{c}}$ values, the best single model used a constant $M( \pm \mathrm{SE})$ of $0.14 \pm 0.02$ and $F$ s that varied by quarter and year (Table 1 ). The estimated annual $F$ s from the best model were $0.76 \pm 0.10$ for 1997 and $0.23 \pm 0.08$ for 1998 . Model-averaged estimates that accounted for the uncertainty in model selection were generally similar but had increased SEs $\left(F_{1997}=0.74 \pm 0.13\right.$; $F_{1998}=0.34 \pm 0.18 ; M_{1997}=0.16 \pm 0.04$; and $\left.M_{1998}=0.12 \pm 0.04\right)$. Relative standard errors $(\mathrm{SE} /$ estimate $\times 100)$ for the model-averaged estimates were $24-33 \%$ for $M$ and $18-54 \%$ for $F$.

The estimated relocation probabilities varied considerably among search occasions, and a reduced model with quarterly relocation probabilities was found to be inadequate (Table 1; Figure $3)$. Relocation probabilities ranged from 0.46 to 1.00 , with a mean of 0.81 , and were insensitive to assumptions about natural and fishing mortality (Figure 3 ). Estimated $F$ s were similarly insensitive to assumptions about natural mortality (Figure 3).

\section{Discussion}

Using this telemetry approach, we obtained estimates of the instantaneous annual natural mortality rate that were consistent between years and reasonably precise (relative SEs of 24-33\%) given the small sample size (6 natural deaths over 2 years). The precision is comparable to results based on large sample sizes with conventional tags. For example, Hearn et al. (1998) obtained a relative SE of $29 \%$ for $M$ when it was constant at 0.2 and a relative SE of $41-54 \%$ when it varied between years in a simulated mark-recapture experiment with 1,000 fish released on each of five tagging occasions and a tag reporting rate of $80 \%$. For a release of 500 fish at each tagging occasion, relative SEs were $42 \%$ for a constant $M$ and 60 $71 \%$ when $M$ varied between years. Xiao and McShane (2000) obtained relative SEs of 9-14\% for estimates of $M$ for the western king prawn Penaeus latisulcatus based on sample sizes of 18,431 tagged females and 23,169 tagged males and auxiliary estimates of fishing effort.

It does not appear likely that our estimates of natural mortality were biased upwards by longterm mortality due to handling and transmitter im-
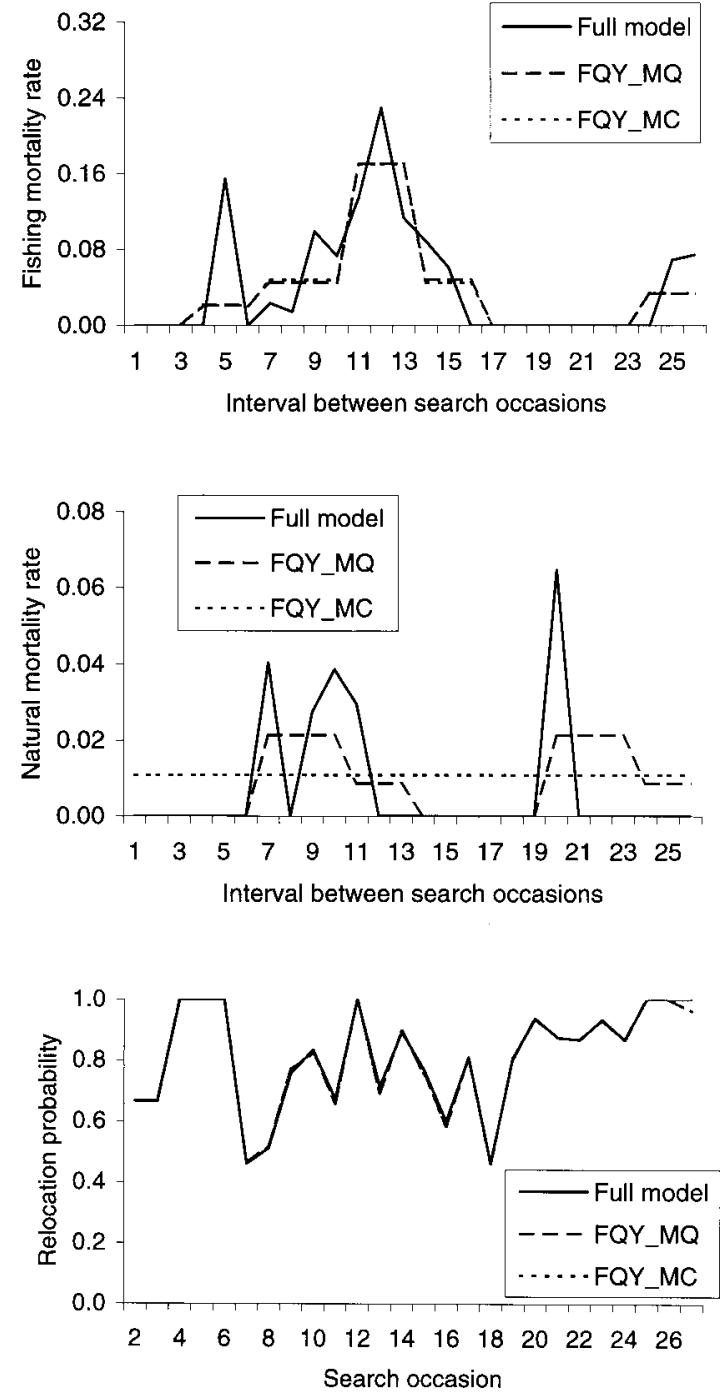

FIGURE 3.-Estimated 4-week instantaneous fishing mortality rates ( $F$; upper panel), instantaneous natural mortality rates $(M$; center panel), and relocation probabilities (lower panel) for Lake Gaston striped bass obtained from a full model, a reduced model allowing for seasonally varying natural mortality (FQY_MQ), and the reduced model that provided the best fit to the data (FQY_MC). The full model uses separate parameters for each occasion except that the final three relocation probabilities are set equal. For the two reduced models, $F$ varies by quarter and year and $M$ varies by quarter (FQY_MQ) or is constant (FQY_MC).

plantation. We captured fish and surgically implanted transmitters at water temperatures of $7-$ $13^{\circ} \mathrm{C}$. Walsh et al. (2000) reported $0 \%$ mortality associated with surgical implantation of transmitters at water temperatures of $12-18^{\circ} \mathrm{C}$. Walsh et 
TABLE 1.-Candidate models fitted to relocations of live and dead fish with the program SURVIV (White 1983) by allowing rates to remain constant (Const) or vary by occasion (Occ), quarter (Qtr), and/or year (Yr). Parameters represent the total number of relocation probabilities $(P)$, fishing mortality rates $(F)$, and natural mortality rates $(M)$ estimated; df is the degrees of freedom and $\Delta \mathrm{AIC}_{\mathrm{c}}$ the difference between the corrected Akaike Information Criterion score for that model and the minimum $\mathrm{AIC}_{\mathrm{c}}$.

\begin{tabular}{|c|c|c|c|c|c|c|c|c|c|c|c|c|c|}
\hline \multicolumn{3}{|c|}{$\begin{array}{l}\text { Temporal variation } \\
\text { of parameters }\end{array}$} & \multirow{2}{*}{$\begin{array}{l}\text { Param- } \\
\text { eters }\end{array}$} & \multirow[b]{2}{*}{ df } & \multirow{2}{*}{$\begin{array}{c}\text { Log } \\
\text { likelihood }\end{array}$} & \multirow[b]{2}{*}{$\mathrm{AIC}_{\mathrm{c}}$} & \multirow{2}{*}{\multicolumn{2}{|c|}{$\begin{array}{c}\text { Model } \\
\Delta \mathrm{AIC}_{\mathrm{c}} \text { likelihood }\end{array}$}} & \multirow{2}{*}{$\begin{array}{l}\text { Akaike } \\
\text { weights }\end{array}$} & \multirow[b]{2}{*}{$F(1997)$} & \multirow[b]{2}{*}{$F(1998)$} & \multirow[b]{2}{*}{$M(1997)$} & \multirow[b]{2}{*}{$M(1998)$} \\
\hline$F$ & $M$ & $P$ & & & & & & & & & & & \\
\hline Occ & Occ & Occ & 76 & 123 & -83.9 & 352.1 & 86.6 & 0.000 & 0.00 & 0.84 & 0.29 & 0.14 & 0.06 \\
\hline Qtr, Yr & Qtr, Yr & Occ & 42 & 157 & -91.7 & 276.4 & 10.9 & 0.004 & 0.00 & 0.75 & 0.25 & 0.14 & 0.07 \\
\hline Qtr & Qtr, Yr & Occ & 38 & 161 & -97.1 & 277.7 & 12.2 & 0.002 & 0.00 & 0.63 & 0.63 & 0.16 & 0.07 \\
\hline $\mathrm{Yr}$ & Qtr, Yr & Occ & 36 & 163 & -100.4 & 279.4 & 13.8 & 0.001 & 0.00 & 0.90 & 0.19 & 0.14 & 0.07 \\
\hline Const & Qtr, Yr & Occ & 35 & 164 & -104.0 & 284.2 & 18.6 & 0.000 & 0.00 & 0.63 & 0.63 & 0.16 & 0.07 \\
\hline Qtr, Yr & Qtr & Occ & 38 & 161 & -92.2 & 267.7 & 2.2 & 0.329 & 0.10 & 0.76 & 0.25 & 0.11 & 0.11 \\
\hline Qtr, Yr & Yr & Occ & 36 & 163 & -94.1 & 266.8 & 1.3 & 0.522 & 0.16 & 0.75 & 0.24 & 0.20 & 0.07 \\
\hline Qtr, Yr & Const & Occ & 35 & 164 & -94.6 & 265.5 & 0.0 & 1.000 & 0.32 & 0.76 & 0.23 & 0.14 & 0.14 \\
\hline Qtr & Qtr & Occ & 34 & 165 & -97.7 & 269.4 & 3.9 & 0.145 & 0.05 & 0.63 & 0.63 & 0.12 & 0.12 \\
\hline Qtr & $\mathrm{Yr}$ & Occ & 32 & 167 & -99.4 & 268.0 & 2.5 & 0.285 & 0.09 & 0.62 & 0.62 & 0.23 & 0.07 \\
\hline Qtr & Const & Occ & 31 & 168 & -100.1 & 267.1 & 1.6 & 0.451 & 0.14 & 0.63 & 0.63 & 0.16 & 0.16 \\
\hline $\mathrm{Yr}$ & Qtr & Occ & 32 & 167 & -101.0 & 271.1 & 5.6 & 0.061 & 0.02 & 0.91 & 0.19 & 0.11 & 0.11 \\
\hline Const & Qtr & Occ & 31 & 168 & -104.7 & 276.2 & 10.7 & 0.005 & 0.00 & 0.65 & 0.65 & 0.12 & 0.12 \\
\hline $\mathrm{Yr}$ & $\mathrm{Yr}$ & Occ & 30 & 169 & -102.7 & 269.9 & 4.4 & 0.111 & 0.04 & 0.91 & 0.18 & 0.20 & 0.08 \\
\hline $\mathrm{Yr}$ & Const & Occ & 29 & 170 & -103.1 & 268.5 & 2.9 & 0.231 & 0.07 & 0.92 & 0.17 & 0.15 & 0.15 \\
\hline Const & $\mathrm{Yr}$ & Occ & 29 & 170 & -106.5 & 275.3 & 9.7 & 0.008 & 0.00 & 0.64 & 0.64 & 0.22 & 0.07 \\
\hline Const & Const & Occ & 28 & 171 & -107.2 & 274.3 & 8.8 & 0.013 & 0.00 & 0.65 & 0.65 & 0.15 & 0.15 \\
\hline Qtr, Yr & Qtr, Yr & Qtr, Yr & 24 & 175 & -117.8 & 286.5 & 20.9 & 0.000 & 0.00 & 0.72 & 0.25 & 0.14 & 0.07 \\
\hline
\end{tabular}

al. (2000) used simulated radio transmitters with external antennas, which would appear to have greater potential for infection than sonic transmitters, which have no antennas.

Telemetry appears to be a much more reliable method of assessing natural or hooking mortality than is observation of dead fish. During our study on Lake Gaston, we estimate that six telemetered fish died of natural causes or hooking mortality, but we observed only two dead striped bass, neither of which was tagged. Bettoli and Osborne (1998) noted that telemetered striped bass in a Tennessee reservoir that died after release by anglers rose to the surface only if they sank in shallow water. Fish that sank in deep, cold water never resurfaced (but were detected by telemetry).

Another advantage of telemetry is that the investigator need not be present when mortality occurs. Searching is labor intensive, but this system required only 2 days every 4 weeks to produce seasonal mortality estimates. Estimates of fishing mortality varied seasonally, in concert with observed changes in fishing pressure. Natural deaths were observed only during summer and fall, when suitable habitat was lacking (Jackson and Hightower 2001), although the model with seasonal estimates of $M$ ranked slightly below the simpler model with a constant $M$. The two primary limitations of our estimates of $M$ were that not all fish were located on each trip (so that the month when natural mortality occurred was not known for two fish) and that the sample size was small because of the low rate of natural mortality and the limited number of telemetered fish. It is important to maintain a high relocation probability in order to estimate seasonal mortality rates reliably. Waters (1999) used our telemetry approach to estimate natural and fishing mortality for a population of largemouth bass Micropterus salmoides in Lucchetti Reservoir in Puerto Rico. Forty-four largemouth bass received sonic tags and were tracked for 372 -week periods. Because $M$ was estimated by 2 -week periods and the relocation probability in the 108-ha reservoir was high (mean, 0.96), Waters (1999) was able to demonstrate that the seasonality of natural mortality corresponded to seasonal patterns of spawning activity.

We also obtained useful information about the fishing mortality of Lake Gaston striped bass through this telemetry approach. The knowledge that fishing mortality substantially exceeds natural mortality could be used by fishery managers to support changes in regulation. Information about the seasonality of fishing mortality could be used to focus creel survey efforts. The estimates of $F$ for this population included some uncertainty because the failure to locate a fish could indicate that the fish experienced transmitter failure or had outmigrated through the turbines without being detected. We consider transmitter failure to be un- 
likely because seven transmitters from fish that died initially owing to gill-net capture and surgery continued to function throughout the study, as did the five transmitters returned by anglers and one recovered from a natural mortality. We also consider it unlikely that the disappearances represent downstream passage through the turbines. In May 1998 , after 28 of the 30 fish thought to have been harvested had disappeared, none were relocated in downstream searches of Roanoke Rapids Lake and the Roanoke River. Also, 20 of the 30 fish were last relocated at the two areas of most intensive fishing within the lake, both a considerable distance upstream of the Gaston dam.

Downstream passage was only observed for 2 of the 51 fish used in our analyses, although these did represent 2 of an estimated 18 telemetered fish at large in the spring of 1998 . We do not have comparable data for 1997 regarding downstream passage during spring periods of high discharge because most of the fish used in our analyses were tagged in May 1997. If a fish did migrate successfully through both the Gaston and Roanoke Rapids dams, the likelihood of relocating that individual was probably low. Nevertheless, six Lake Gaston striped bass were relocated in Albemarle Sound in October 1997-April 1998 during a concurrent telemetry study of Atlantic sturgeon Acipenser oxyrinchus. Those fish were among the ones initially released but not included in our analysis. If some of the 51 fish included in our analysis were successful in migrating through the two dams, then fishing mortality would be overestimated.

We did not include in our analysis information from angler reports of recovered transmitters. The reporting rate for the implanted transmitters appeared to be quite low, since 30 of the 51 fish are considered to have been harvested during the study but only five transmitters were returned by anglers. In addition, information on the timing of harvest provided by the anglers that returned transmitters was generally imprecise and in at least one case was almost certainly inaccurate. (One angler returned a functioning transmitter in November 1998 and indicated that the fish was caught within the prior 3 weeks; however, our last relocation of that fish in Lake Gaston was in August 1997.)

This telemetry approach is most applicable in a closed system such as a lake or river section blocked by dams. Lake Gaston is about $54 \mathrm{~km}$ in length and has a surface area of 8,215 ha; it may represent a reasonable upper bound on the size of a system that can be searched effectively by a small crew. Either sonic or radio tags could be used for this type of study, although radio signals become attenuated with depth and could therefore be undetectable if a fish moved into deep water or died and sank into deep water (Osborne and Bettoli 1995). It may be advantageous to consider staggered releases of telemetered fish so that an adequate sample size is maintained throughout the study. It is also important to maintain a high probability of relocating telemetered fish so that the timing of mortality events will be determined reliably. The number of search occasions per year would depend on the expected seasonality in mortality rates. A long interval between search occasions would be inappropriate if mortality is to be related to fishing pressure or environmental conditions that vary substantially within the interval. If appropriate, a longer interval between search occasions could be advantageous if it allowed for more intensive searching on each occasion. Another advantage would be the longer lifetime of transmitters that were programmed to switch off between search occasions. Transmitters that last for more than 1 year are more cost effective and make it possible to compare seasonal mortality estimates among years. It may also be beneficial to apply an external tag to telemetered fish in order to better assess the link between harvesting and declines in the number of relocated fish. Reports of telemetered fish with external tags that were caught and released could also be helpful in separating hooking mortality from true natural mortality.

This approach can be considered an intermediate step in a hierarchy of telemetry-based methods for estimating mortality rates. The model developed by Pollock et al. (1995) uses relocation data for live and dead individuals to estimate total mortality rate. The model developed in this study requires relocation data for live individuals and those that died of natural causes, in order to estimate natural and fishing mortality rates. A further extension of this model may be possible in systems where all harvested individuals would be encountered (for example, through a check station). For that case, relocation data for live individuals, those that were harvested, and those that died of natural causes would provide more precise estimates of natural and fishing mortality rates than the approach we used. A practical problem for this extended model may be the requirement that the relocation probabilities be equal, which is unlikely to be met because harvested individuals would probably not be encountered using telemetry methods. 
In some systems, there may be merit to combining a large-scale conventional tagging study with the more intensive telemetry design used here. Conventional tags are inexpensive and can be applied to a large sample of fish to estimate total mortality rates reliably. If an external estimate of the reporting rate is available, conventional tagging studies can also be used to estimate fishing and natural mortality rates reliably (Hoenig et al. 1998a, 1998b). Telemetry studies are more labor intensive and costly, but they can be done with a small sample of fish to partition total mortality into that from fishing and that from natural sources without knowledge of the reporting rate. A study combining both types of tags would also provide an estimate of the tag reporting rate for conventional tags. We believe model development, simulation, and a field test of this combined approach deserves immediate attention from biometricians and fisheries biologists.

\section{Acknowledgments}

We thank Bill Collart, Wayne Jones, and Scott Van Horn for collecting the fish used in this study and Bob Graham for providing water quality data. Kent Nelson and Bob Graham provided helpful comments on an earlier draft of this report. Funding was provided by the North Carolina Wildlife Resources Commission (Federal Aid in Fish Restoration, project F-30-11) and Virginia Power.

\section{References}

Bendock, T., and M. Alexandersdottir. 1993. Hooking mortality of chinook salmon released in the Kenai River, Alaska. North American Journal of Fisheries Management 13:540-549.

Bettoli, P. W., and R. S. Osborne. 1998. Hooking mortality and behavior of striped bass following catch and release angling. North American Journal of Fisheries Management 18:609-615.

Burnham, K. P., and D. R. Anderson. 1998. Model selection and inference: a practical information-theoretic approach. Springer-Verlag, New York.

Burnham, K. P., D. R. Anderson, G. C. White, C. Brownie, and K. H. Pollock. 1987. Design and analysis methods for fish survival experiments based on release-recapture data. American Fisheries Society Monograph 5, Bethesda, Maryland.

Haeseker, S. L., J. T. Carmichael, and J. E. Hightower. 1996. Summer distribution and condition of striped bass within Albemarle Sound, North Carolina. Transactions of the American Fisheries Society 125: 690-704.

Hearn, W. S., R. L. Sandland, and J. Hampton. 1987. Robust estimation of the natural mortality rate in a completed experiment with variable fishing inten- sity. Journal du Conseil International pour l'Exploration de la Mer 43:107-117.

Hearn, W. S., K. H. Pollock, and E. Brooks. 1998. Preand post-season tagging models: estimation of reporting rate and fishing and natural mortality rates. Canadian Journal of Fisheries and Aquatic Sciences 55:199-205.

Hightower, J. E., and J. R. Jackson. 2000. Distribution and natural mortality of stocked striped bass in Lake Gaston, North Carolina. North Carolina Wildlife Resources Commission, Division of Inland Fisheries, Federal Aid in Sport Fish Restoration project F-30-13, Study 5, Final Report, Raleigh.

Hilborn, R., and C. J. Walters. 1992. Quantitative fisheries stock assessment: choice, dynamics, and uncertainty. Chapman and Hall, New York.

Hoenig, J. M., N. J. Barrowman, W. S. Hearn, and K. H. Pollock. 1998a. Multiyear tagging studies incorporating fishing effort data. Canadian Journal of Fisheries and Aquatic Sciences 55:1466-1476.

Hoenig, J. M., N. J. Barrowman, K. H. Pollock, E. N. Brooks, W. S. Hearn, and T. Polacheck. 1998b. Models for tagging data that allow for incomplete mixing of newly tagged animals. Canadian Journal of Fisheries and Aquatic Sciences 55:1477-1483.

Jackson, J. R., and J. E. Hightower. 2001. Reservoir striped bass movements and site fidelity in relation to seasonal patterns in habitat quality. North American Journal of Fisheries Management 21:34-45.

Lee, W. C., and E. P. Bergersen. 1996. Influence of thermal and oxygen stratification on lake trout hooking mortality. North American Journal of Fisheries Management 16:175-181.

Osborne, R., and P. W. Bettoli. 1995. A reusable ultrasonic tag and float assembly for use with large pelagic fish. North American Journal of Fisheries Management 15:512-514.

Pascual, M. A., and O. O. Iribarne. 1993. How good are empirical predictions of natural mortality? Fisheries Research 16:17-24.

Pollock, K. H., S. R. Winterstein, and M. J. Conroy. 1989a. Estimation and analysis of survival distributions for radio-tagged animals. Biometrics 45: 99-109.

Pollock, K. H., S. R. Winterstein, C. M. Bunck, and P. D. Curtis. 1989b. Survival analysis in telemetry studies: the staggered entry design. Journal of Wildlife Management 53:7-15.

Pollock, K. H., C. M. Bunck, S. R. Winterstein, and C.L. Chen. 1995. A capture-recapture survival analysis model for radio-tagged animals. Journal of Applied Statistics 22:661-672.

Quinn, T. J. II, and R. B. Deriso. Quantitative Fish Dynamics. 1999. Oxford University Press, Oxford, UK.

Ricker, W. E. 1975. Computation and interpretation of biological statistics of fish populations. Fisheries Research Board of Canada Bulletin 191.

Trent, T. T., and O. J. Rongstad. 1974. Home range and survival of cottontail rabbits in southwestern Wisconsin. Journal of Wildlife Management 38:459472 . 
Vetter, E. F. 1988. Estimation of natural mortality in fish stocks: a review. Fishery Bulletin 86:25-43.

Walsh, M. G., K. A. Bjorgo, and J. J. Isely. 2000. Effects of implantation method and temperature on mortality and loss of simulated transmitters in hybrid striped bass. Transactions of the American Fisheries Society 129:539-544.

Waters, D. S. 1999. Spawning season and mortality of adult largemouth bass (Micropterus salmoides) in a tropical reservoir. Master's thesis. North Carolina State University, Raleigh.
White, G. C. 1983. Numerical estimation of survival rates from band recovery and biotelemetry data. Journal of Wildlife Management 47:716-728.

White, G. C., and R. A. Garrott. 1990. Analysis of wildlife radio-tracking data. Academic Press, San Diego, California.

Xiao, Y., and P. McShane. 2000. Estimation of instantaneous rates of fishing and natural mortalities from mark-recapture data on the western king prawn Penaeus latisulcatus in the Gulf St. Vincent, Australia, by conditional likelihood. Transactions of the American Fisheries Society 129:1005-1017. 